\title{
Differences in Brain Waves of Normal Persons and Stroke Patients during Action Observation and Motor Imagery
}

\author{
Junghee Kim, PT, MSc ${ }^{1)}$, Byounghee Lee, PT, PhD²), Hyun Suk LeE ${ }^{2)}$, Kil Ho Shin ${ }^{2)}$, \\ Min JU KIM ${ }^{2)}$, EsTHER SON ${ }^{2)}$ \\ 1) Graduate School of Physical Therapy, Sahmyook University, Republic of Korea \\ 2) Department of Physical Therapy, Sahmyook University: 815 Hwarang-ro, Nowon-gu, Seoul 139-742, \\ Republic of Korea
}

\begin{abstract}
Purpose] The purpose of this study was to examine the changes in brain waves between action observation and motor imagery of stroke patients and normal subjects, and to compare them. [Methods] Twelve stroke patients and twelve normal persons participated in this research. Each group executed action observation and the motor imagery training for 3 minutes, and before and during each intervention the brain waves were measured for 3 minutes, and the relative alpha power and relative beta power analyzed. [Results] Both normal persons and stroke patients showed significant differences in relative alpha power during action observation, but no significant difference in relative alpha power was found during motor imagery. The relative beta power increased similarly in both groups but it was more significantly different during action observation than during motor imagery. [Conclusion] Both action observation and motor imagery can be used as a therapeutic method for motor learning. However, action observation induces stronger cognitive activity, so for the stroke patients who have difficulty with fine motor representation, action observation might be a more effective therapy.

Key words: Action observation, Motor imagery, Stroke
\end{abstract}

(This article was submitted Jul. 24, 2013, and was accepted Aug. 28, 2013)

\section{INTRODUCTION}

Active physical training activates the afferent sensory pathway and is the basis of motor recovery and motor learning ${ }^{1)}$. Mosts motor skills are acquired by physical activity, but they can also be acquired by cognitive interventions like action observation or motor imagery ${ }^{2}$. Motor imagery is the mental representation of the performance without doing the action and it is an internal stimulus which induces indirect experience ${ }^{3)}$. Motor imagery is known to induce muscle activity and brain activity similar to that induced when performing the actual activity ${ }^{4-7)}$. Action observation is a cognitive intervention used to treat athletes, ordinary subjects, and patients with motor dysfunction to increase their motor skills and learning. It is based on mirror neuron activity which is excited when observing the actual action of other person ${ }^{8,9)}$. Action observation excites the primary motor area of the cortex, creating a kinesthetic memory, and the cognitive process when related to motor learning, imitation learning, and comprehension of the action of others ${ }^{10)}$. It is a cognitive intervention like motor imagery

*Corresponding author. Byuoughee Lee (E-mail: 3679@syu. ac.kr)

(C2014 The Society of Physical Therapy Science. Published by IPEC Inc. This is an open-access article distributed under the terms of the Creative Commons Attribution Non-Commercial No Derivatives (by-ncnd) License $<$ http://creativecommons.org/licenses/by-nc-nd/3.0/>. which can be used to treat disuse caused by the inactivity of patients due to pain, or those who cannot move due to injury. Many studies have demonstrated the effectiveness of motor learning as a training method ${ }^{1,11,12)}$. However, most studies of stroke patients, have only analyzed changes in body function before and after training, and few have tried to apprehend changes in brain activity. Therefore, in this research we investigated and compared the brain waves of stroke patients and normal persons under the conditions of action observation and the motor imagery

\section{SUBJECTS AND METHODS}

There were 24 subjects, 12 normal individuals in their twenties and 12 stroke patients. Only stroke patients who were chronic patients with more than 6 months since onset, who had a MMSE score of 24 , no cognitive decline and no motor aphasia were selected. We excluded those who had limited ability of on planning for action and imagery and also those who had depression or dementia symptoms. The normal patients were selected from among healthy university students those who had no neurological impairment or psychological problems. This study was approved by the Committee of Ethics of Shamyook University.

This study measured the changes in brain waves induced by action observation and motor imagery. We measured subjects' brain waves at rest for 3 minutes. Then, the subjects performed action observation and motor imaginary for 
Table 1. Changes of brain waves $(n=24)$

\begin{tabular}{|c|c|c|c|c|c|c|c|}
\hline & \multirow[b]{2}{*}{ channel } & \multicolumn{3}{|c|}{ normal individuals $(\mathrm{n}=12)$} & \multicolumn{3}{|c|}{ stroke patients $(\mathrm{n}=12)$} \\
\hline & & pretest & $\mathrm{AO}$ & MI & pretest & $\mathrm{AO}$ & MI \\
\hline \multirow{8}{*}{$\begin{array}{c}\text { Relative } \\
\text { Alpha }\end{array}$} & Fp1 & $0.2001(0.1420)$ & $0.0149 \pm 0.0072^{*}$ & $0.2195 \pm 0.1525^{\dagger}$ & $0.1107 \pm 0.0915$ & $0.0381 \pm 0.0439^{*}$ & $0.1192 \pm 0.0965^{\dagger}$ \\
\hline & $\mathrm{Fp} 2$ & $0.2075(0.1527)$ & $0.0143 \pm 0.0069^{*}$ & $0.2220 \pm 0.1628^{\dagger}$ & $0.1275 \pm 0.1082$ & $0.0351 \pm 0.0473^{*}$ & $0.1438 \pm 0.1204^{\dagger}$ \\
\hline & $\mathrm{C} 3$ & $0.2891 \pm 0.1679$ & $0.0715 \pm 0.0355^{*}$ & $0.2906 \pm 0.1465^{\dagger}$ & $0.1783 \pm 0.1240$ & $0.0776 \pm 0.0328^{*}$ & $0.2141 \pm 0.1316^{\dagger}$ \\
\hline & $\mathrm{C} 4$ & $0.2982 \pm 0.1702^{*}$ & $0.0732 \pm 0.0343$ & $0.3067 \pm 0.1550^{\dagger}$ & $0.1940 \pm 0.1401$ & $0.0834 \pm 0.0344^{*}$ & $0.2193 \pm 0.1265^{\dagger}$ \\
\hline & $\mathrm{P} 3$ & $0.2636 \pm 0.1698$ & $0.1136 \pm 0.0531^{*}$ & $0.2735 \pm 0.1550^{\dagger}$ & $0.1473 \pm 0.0900$ & $0.1124 \pm 0.0611$ & $0.1866 \pm 0.0973^{\dagger}$ \\
\hline & P4 & $0.2537 \pm 0.1514$ & $0.0876 \pm 0.0402^{*}$ & $0.2811 \pm 0.1575^{\dagger}$ & $0.1709 \pm 0.1203$ & $0.1040 \pm 0.0550^{*}$ & $0.2113 \pm 0.1415^{\dagger}$ \\
\hline & $\mathrm{O} 1$ & $0.3986 \pm 0.1884$ & $0.1553 \pm 0.0564^{*}$ & $0.4078 \pm 0.1808^{\dagger}$ & $0.2357 \pm 0.1664$ & $0.1512 \pm 0.0651$ & $0.3014 \pm 0.1638^{\dagger}$ \\
\hline & $\mathrm{O} 2$ & $0.4205 \pm 0.1957$ & $0.1150 \pm 0.0579^{*}$ & $0.4350 \pm 0.1940^{\dagger}$ & $0.1979 \pm 0.1591$ & $0.1357 \pm 0.0506$ & $0.2880 \pm 0.1685^{\dagger}$ \\
\hline \multirow{8}{*}{$\begin{array}{c}\text { Relative } \\
\text { Beta }\end{array}$} & Fp1 & $0.0570 \pm 0.0287$ & $0.0119 \pm 0.0077^{*}$ & $0.0634 \pm 0.0271^{\dagger}$ & $0.0675 \pm 0.0440$ & $0.0741 \pm 0.0850^{\S}$ & $0.1072 \pm 0.1109$ \\
\hline & $\mathrm{Fp} 2$ & $0.0563 \pm 0.0291$ & $0.0134 \pm 0.0084^{*}$ & $0.0633 \pm 0.0279^{\dagger}$ & $0.0604 \pm 0.0440$ & $0.0700 \pm 0.0833^{\S}$ & $0.0777 \pm 0.0706$ \\
\hline & $\mathrm{C} 3$ & $0.0923 \pm 0.0415$ & $0.0805 \pm 0.0514$ & $0.1060 \pm 0.0453^{*}$ & $0.0924 \pm 0.0415$ & $0.0805 \pm 0.0514^{*}$ & $0.1060 \pm 0.0453^{*}$ \\
\hline & $\mathrm{C} 4$ & $0.0809 \pm 0.0345$ & $0.0700 \pm 0.0251$ & $0.0983 \pm 0.0531$ & $0.0794 \pm 0.0417$ & $0.1236 \pm 0.0845^{*} \S$ & $0.1235 \pm 0.0845$ \\
\hline & $\mathrm{P} 3$ & $0.0888 \pm 0.0365$ & $0.1192 \pm 0.3000$ & $0.1233 \pm 0.6512$ & $0.0992 \pm 0.0449$ & $0.1588 \pm 0.0796^{*}$ & $0.1322 \pm 0.0593$ \\
\hline & P4 & $0.1067 \pm 0.0601$ & $0.1070 \pm 0.0440$ & $0.1214 \pm 0.0820$ & $0.1023 \pm 0.0506$ & $0.1543 \pm 0.0875^{*}$ & $0.1324 \pm 0.0732$ \\
\hline & $\mathrm{O} 1$ & $0.1023 \pm 0.0587$ & $0.1373 \pm 0.0445^{*}$ & $0.1187 \pm 0.0651^{*}$ & $0.0783 \pm 0.0441$ & $0.1518 \pm 0.0576^{*}$ & $0.1252 \pm 0.0554^{* \dagger}$ \\
\hline & $\mathrm{O} 2$ & $0.0970 \pm 0.0602$ & $0.1336 \pm 0.0413^{*}$ & $0.1160 \pm 0.0749^{*}$ & $0.0766 \pm 0.0418$ & $0.1743 \pm 0.0696^{*}$ & $0.1285 \pm 0.0503^{* \dagger}$ \\
\hline
\end{tabular}

Values are mean (SD). Fp1, frontopolar1; Fp2, frontopolar2; C3, central lobe3; C4, central lobe4; P3, parietal lobe3; P4, parietal 4; O1, occipital lobe1; O2, occipital lobe 2; AO, action observation; MI, motor imagery; ${ }^{*} \mathrm{p}<0.05$ between the pretest of $\mathrm{AO}$ or MI; ${ }^{\dagger} \mathrm{p}<0.05$ between the within group $\mathrm{AO}$ and $\mathrm{M} ;{ }^{\S} \mathrm{p}<0.05$ between the pretest of normal individuals and stroke in $\mathrm{AO}$.

3 minutes. There were 3 minutes of resting time the between the interventions, and to minimize the interference effect, half of each group were randomly selected and performed action observation after motor imagery again. The action observation training was composed of task-oriented movements. Subjects watched a video displaying the actions of breathing normally at rest, pelvic anteroposterior tilting in the sitting position, trunk left and right rotation on a chair and, stand to sit. Motor imagery was also composed of the same contents as the action observation, except the contents were delivered by oral explanation and the subjects had to imagine the actions. While doing the action observation and the motor imagery the subjects were educated not to adjust their posture or their hands and feet. Electronic devices to minimize the interference of unnecessary waves while measuring the brain waves of the subjects.

Poly-I (Laxtha INC., Daejeon, Korea) was used to take EEG measurements. EEG electrodes were attached to eight places on the scalp using the monopolar derivation method. The eight places were: the frontopolar 1 (Fp1), frontopolar 2 (Fp2), central $3(\mathrm{C} 3)$, central $4(\mathrm{C} 4)$, parietal 3(P3), parietal 4(P4), occipital $1(\mathrm{O} 1)$, and occipital $2(\mathrm{O} 2)$, in accordance with the International 10-20 system. Moreover, a reference electrode and a ground reference electrode were placed behind the right earlobe and the left earlobe, respectively. The electrodes used were gold-plated disc-shaped ones, and they were attached using glue for EEG electrodes (ElefixZ401Ce, Japan).

For EEG data analysis, a quantitative analysis was conducted using Telescan 2.98 (laxtha INC., Daejeon, Korea). From 3 minutes of EEG raw data, 160 seconds of each measurement after excluding the first and last 10 seconds was analyzed. In addition, only EEG waves between 5 and
$50 \mathrm{~Hz}$ were analyzed. Delta waves $(0.5-5 \mathrm{~Hz})$ were ignored because they are very likely to compromised by eye blinks $(2-4 \mathrm{~Hz})$ or head movements due to an unstable posture $(0.5-1 \mathrm{~Hz})$. Raw EEG data were converted into frequencies using fast Fourier transforms (FFT). The value calculated here is called absolute band power, but in this study, relative band power, which indicates the ratio of the absolute band power at a certain frequency to the absolute band power, was calculated in order to correct differences among the subjects in EEG due to variations in scalp thickness and level of tension. Then, relative alpha power $(8-13 / 4-50 \mathrm{~Hz})$ and relative beta power $(13-20 / 4-50 \mathrm{~Hz})$ were analyzed.

SPSS statistical package version 17.0 (SPSS Inc., Chicago, IL, USA) was used for statistical analysis. The paired $t$ test was used determine the significance of changes in values from pretest to posttest within a group. The independent $t$ test was used to determine the significance of the changes between the groups.

\section{RESULTS}

The average ages of subjects in the stroke group and the normal group were 56.0 years and 22.3 years. The average height of subjects in the stroke group and the normal group were $165.6 \mathrm{~cm}$ and $171.2 \mathrm{~cm}$. The average weight of subjects in the stroke group and the normal group were $68.6 \mathrm{~kg}$ and $62.6 \mathrm{~kg}$, and the average time after onset of stroke group was 132.7 days.

The brain wave analysis of the normal subjects and the stroke patients and the changes of the brain wave induced by the actions are shown in the Table 1. 


\section{DISCUSSION}

A brain wave is an electrical signal which appears when the brain exchanges information, and it has important information about brain activity, showing specific changes according to mental status and activity ${ }^{13)}$. Alpha waves (8-13 $\mathrm{Hz}$ ) increase during rest in comfort, and decrease with the onset of cognitive activity, which is known as the alphablocking phenomenon. Therefore, decreases in relative alpha power mean the cognitive activity of the brain has been increased ${ }^{14)}$. Beta waves $(14-30 \mathrm{~Hz})$ decrease during cognitive information processing activity or physical activity, and an increase in the relative beta power indicates cognitive function, especially when learning new information since the cranial nerve spends a lot of energy ${ }^{15)}$.

The relative alpha power of the normal group during action observation significantly decreased compared to the pre-experiment, while during motor imagery it showed no significant changes. Also, in the comparison of the relative alpha power between action observation and motor imagery, during action observation the relative alpha power was lower in all areas. The relative beta power during action observation of the Fp1, Fp2, O1, O2 areas showed significant increases compared to rest, and motor imagery, the condition $\mathrm{C} 3, \mathrm{O} 1, \mathrm{O} 2$ areas showed significant changes. In the comparison of the relative beta wave between the two activities the Fp1, Fp2 areas showed higher relative beta power during action observation (Table 1). The Fp1 and Fp2 areas of the prefrontal lobe are known to participate when subjects concentrate on movement and cognitive activity of new circumstances ${ }^{16)}$.

According to Pfurtscheller et al. When normal subjects performed a goal-oriented grabbing action, the alpha waves decreased in the sensory motor area and the occipital lobe, but they did not report the area differences ${ }^{17)}$.

During action observation by the stroke group, all the areas measured showed significantly low levels of relative alpha power, except P3, O1, and O2. During motor imagery, the alpha power was not significantly different from rest, and in the comparison of the relative alpha power between the two activities action observation showed lower relative alpha power in all areas. In the analysis of the relative beta wave all the areas showed significant increase in the relative alpha power, except Fp1, Fp2, during motor imagery the relative beta power was significantly greater in the areas of $\mathrm{O} 1$ and $\mathrm{O} 2$.

Action observation increases the cortex excitability of the primary motor area which initiates the cognitive processes related to formation of kinesthetic memory, motor learning, imitation learning, and understanding and comprehending the purpose of the movement ${ }^{10)}$. However, motor imagery can pose difficulties for subjects trying to imagine the whole process, while the exact motor representation of the task was made ${ }^{18)}$. The results of this study also show that the brain wave changes of stroke patients were less in motor imagery than in action observation, and this observation supports the proposal, that after brain injury, such as the stroke, action observation training is more effective than motor imagery as a therapeutic approach in rehabilitation ${ }^{19)}$.

In the comparison of the relative alpha power and the relative beta power of the stroke group with those of the normal group no differences were found in the frequency of occurrence of the relative alpha power and the relative beta power, except for the relative beta power of Fp1, Fp2 and $\mathrm{C} 4$ during action observation. This means that there were no brain wave differences between the stroke group and the normal group during action observation and motor imagery. This implies that the effects of the two activities are expected to be the same in stroke patients as in normal individuals. The significant differences in the relative beta power of the stroke group in the areas of Fp1, Fp2, and C4 observed during action observation mean that action observation induces higher levels of cognitive activity than the motor imagery. Real performance, action observation and motor imagery basically use the same neurological mechanism ${ }^{20)}$, and action observation and motor imagery can be said to be the off-line operation of the motor system ${ }^{1}$.

In conclusion, under the same conditions, action observation can induce stronger cognitive activity as a form of internal stimulus than motor imagery. We suggest that action observation is an effective cognitive intervention when motor representation is difficult. However the differences in cognitive activity can change according to the characteristics of the task. In the motor learning process, the researcher needs to know the cognitive levels and the details of the learning task before conducting cognitive interventions such as action observation or motor imagery and to prepare a systematic intervention program.

\section{REFERENCES}

1) Mulder $T$ : Motor imagery and action observation: cognitive tools for rehabilitation. J Neural Transm, 2007, 114: 1265-1278. [Medline] [CrossRef]

2) Petrosini L, Graziano A, Mandolesi L, et al.: Watch how to do it! New advances in learning by observation. Brain Res Brain Res Rev, 2003, 42: 252-264. [Medline] [CrossRef]

3) Gentili R, Papaxanthis C, Pozzo T: Improvement and generalization of arm motor performance through motor imagery practice. Neuroscience, 2006, 137: 761-772. [Medline] [CrossRef]

4) Ehrsson HH, Geyer S, Naito E: Imagery of voluntary movement of fingers, toes, and tongue activates corresponding body-part-specific motor representations. J Neurophysiol, 2003, 90: 3304-3316. [Medline] [CrossRef]

5) Filimon F, Nelson JD, Hagler DJ, et al.: Human cortical representations for reaching: mirror neurons for execution, observation, and imagery. Neuroimage, 2007, 37: 1315-1328. [Medline] [CrossRef]

6) Stinear CM, Byblow WD: Motor imagery of phasic thumb abduction temporally and spatially modulates corticospinal excitability. Clin Neurophysiol, 2003, 114: 909-914. [Medline] [CrossRef]

7) Stippich C, Ochmann H, Sartor K: Somatotopic mapping of the human primary sensorimotor cortex during motor imagery and motor execution by functional magnetic resonance imaging. Neurosci Lett, 2002, 331: 50-54. [Medline] [CrossRef]

8) Léonard G, Tremblay F: Corticomotor facilitation associated with observation, imagery and imitation of hand action: a comparatioe studassocyoung and old adults. Exp Brain Res, 2007, 177: 167-175. [Medline] [CrossRef]

9) Rochat MJ, Caruana F, Jezzini A, et al.: Responses of mirror neurons in area F5 to hand and tool grasping observation. Exp Brain Res, 2010, 204: 605-616. [Medline] [CrossRef]

10) Maeda F, Kleiner-Fisman G, Pascual-Leone A: Motor facilitation while observing hand action: specificity of the effect and role of observer's orientation. J Neurophysiol, 2002, 87: 1329-1335. [Medline]

11) Ertelt D, Small S, Solodkin A, et al.: Action observation has a positive impact on rehabilitation of motor deficits after stroke. Neuroimage, 2007, 36: T164-T173. [Medline] [CrossRef] 
12) Hwang SY, Wei J, Westhoff JH, et al.: Differential functional interaction of two Ves1/Homer protein isoforms with ryanodine receptor type 1: a novel mechanism for control of intracellular calcium signaling. Cell Calcium, 2003, 34: 177-184. [Medline] [CrossRef]

13) Wing K: Effect of neurofeedback on motor recovery of a patient with brain injury: a case study and its implications for stroke rehabilitation. Top Stroke Rehabil, 2001, 8: 45-53. [Medline] [CrossRef]

14) Pfurtscheller G, Neuper C, Pichler-Zalaudek K, et al.: Do brain oscillations of different frequencies indicate interaction between cortical areas in humans? Neurosci Lett, 2000, 286: 66-68. [Medline] [CrossRef]

15) Ray WJ, Cole HW: EEG alpha activity reflects attentional demands, an beta activity reflects emotional and cognitive processes. Science, 1985, 228: 750-752. [Medline] [CrossRef]

16) Praamstra P, Boutsen L, Humphreys GW: Frontoparietal control of spatial attention and motor intention in human EEG. J Neurophysiol, 2005, 94 764-774. [Medline] [CrossRef]

17) Craighero L, Bello A, Fadiga L, et al.: Hand action preparation influences the responses to hand pictures. Neuropsychologia, 2002, 40: 492-502. [Medline] [CrossRef]

18) Smith D, Holmes P: The effect of imagery modality on golf putting performance. J Sport Exerc Psychol, 2004, 26: 385-395.

19) Celnik P, Stefan K, Hummel F, et al.: Encoding a motor memory in the older adult by action observation. Neuroimage, 2006, 29: 677-684. [Medline] [CrossRef]

20) Dechent P, Merboldt KD, Frahm J: Is the human primary motor cortex involved in motor imagery? Brain Res Cogn Brain Res, 2004, 19: 138-144. [Medline] [CrossRef 